\title{
Comparative Analysis of Implementation of Solar PV Systems Using the Advanced SPECA Modelling Tool and HOMER Software: Kenyan Scenario
}

\author{
S. Kibaara ${ }^{a^{*}}$, D. K. Murage ${ }^{\text {b }}$, P. Musau ${ }^{\text {c }}$, M. J. Saulo ${ }^{\text {a }}$ \\ ${ }^{a}$ Technical University of Mombasa, Mombasa, Kenya. \\ ${ }^{b}$ Jomo Kenyatta University, Juja, Kenya. \\ ${ }^{c}$ University of Nairobi, Nairobi, Kenya.
}

Received 25 January 2020; Revised 23 February 2020; Accepted 28 February 2020; Published 01 March 2020

\begin{abstract}
Globally, attention has been focused on the pollution and exhaustion of fossil fuels allied to conventional energy sources, while non-conventional energy/renewable energy sources have always been considered clean and environmentally friendly. Of the two, the non-conventional (renewable) is being preferred because it is believed to be more environmentally friendly. Renewable Energy Technologies (RETs), especially Solar Photovoltaics, have seen many plants being constructed to either supplement the grid or as alternatives for those far from the grid. Solar Photovoltaics plants occupy large tracts of land that would have been used for other economic activities for revenue generation, such as agriculture, forestry, or tourism at archaeological sites. The negative impacts slow down the application of Solar PV, but a modelling tool that can easily and quantitively assess the impacts in monetary form would accelerate the Solar PV application. The work presents a developed modelling tool that is able to assess not only the techno-economic impacts but also the environmental impacts in monetary form, allowing one to be able to determine the viability of a plant in a given region. The results are compared with those of the HOMER software.
\end{abstract}

Keywords: SPECA Tool; HOMER; Environment; Solar PV.

\section{Introduction}

Due to the depletion of fossil fuels and their GHG emissions, global attention has shifted largely to the generation of electricity using hybrid renewable energy systems [1]. The governments of many nations across the world have also given direct nomination to these renewable energy systems through tradable green certificates. This has spurred tremendous efforts in the exploration of renewable energy options, particularly in rural areas where grid connection is impractical due to rugged terrain and a small population [1, 2]. In this regard, a number of software tools have been suggested for the simulation and optimization of HRES. HOMER, SAM, HOGA, and RETScreen are some of the most popular Techno-Economic tools [3]. HOMER has been regarded as the global standard for optimization of HRES and is one of the most widely used tools for optimization and sensitivity analysis [4, 5]. According to Acakpovi et al. (2015) [4], it is a computer tool that is able to simplify and design a standalone or grid-tied micro-grid. On the other hand, HOMER has demerits such as the inability to show the optimization techniques adopted in the simulation

* Corresponding author: samuelkariuki@tum.ac.ke

dol http://dx.doi.org/10.28991/HIJ-2020-01-01-02

$>$ This is an open access article under the CC-BY license (https://creativecommons.org/licenses/by/4.0/).

(C) Authors retain all copyrights. 
process. Furthermore, HOMER does not provide flexibility to the user to set the optimization constraints, especially in cases where the prices of electricity generation fuels are already fixed by the markets. In a nutshell, despite its big name and global attention, HOMER does not meet all the needs of HRES optimization problems. Therefore, scientists have resulted in searching for other HRES optimization and sizing options based on rigorous mathematical modelling [4].

\section{Previous Work on Optimization and Sizing of HRES}

A variety of studies have applied different optimization techniques to the sizing of HRES. For instance, Amer et al. (2013) [6] proposed the cost reduction of HRES using particle swarm optimization (PSO). Bansal et al. (2011) [7] in their simulations of a hybrid wind solar and battery used a meta-heuristic particle swarm optimization for cost reduction. Ram et al. (2013) [8] in their design of a standalone solar -wind hybrid with a diesel generator used PSO to find the optimal sizes of each to meet the existing load. In addition, Lotfi et al. (2013) [9] proposed the use of the imperial competitive algorithm, PSO, to establish the optimal configuration of a hybrid wind-solar and batteries. Other superior cost reduction optimization techniques, such as Hybrid Genetic algorithms (GA) with PSO (HGAPSO) [10], were used for the optimization of HRES. This algorithm overcomes the low speed convergence attributed to GA and the premature convergence of PSO, which means tremendous speed of convergence and hence global convergence. The combination of PSO and simulated annealing (SA) developed by Idoumghar et al. (2011) [11] overcame the premature convergence of PSO.

ARENA 12 which is a commercial software was used by Ekren and Ekren (2009) [12] for the simulation and optimization of various HRES at various loads. The optimal size of PV- biomass hybrid system was configured by HOMER in Egypt [13]. Ashok (2007) [14] configured the sizes of wind solar and batteries using analytical models. The speed of the wind, direct normal irradiation (DNI) and the load requirement were the main factors used to control the micro grid. The results obtained were used for calibration of the optimal power required for the load.

Important to note is all these modern tools for optimization and simulation of HRES have a clear focus on cost reduction and size configuration. The cost reduction in this case refers to the capital cost. These techniques and tools fail to address the overall reduction of LCOE which is a quotient of the life cycle costs (capital costs, operation and maintenance costs, replacement costs, salvage cost) and the life time energy generated. Also missing in all these optimization techniques and simulation tools are the levelized cost of externalities (LECOE), that is, the environmental impacts of these energy sources. This paper therefore seeks to bridge the existing knowledge gap by showing the mathematical development of the SPECA model which fills the gap as it is able to determine the configuration of solar PV and clearly demonstrates the indirect costs (externalities) incurred when generating electricity from PV. In this paper the SPECA model and HOMER software will be used to simulate PV for Turkana District in Kenya and results obtained shall be compared based on the energy generated, cash flows, environmental impacts and LCOE.

The first part of this paper presents the detailed SPECA model development followed by the available resources and load requirements for testing. Simulations are finally carried out using the SPECA model and the HOMER software and the results tabulated for comparison.

\section{Methodology}

The core objective of this paper is the acknowledgement that nature has value in it, and therefore in the decisions to install and test the techno economic viability of solar PV the environmental impacts should be taken into consideration. Therefore, in the development of the SPECA model environmental impacts of solar PV have been identified quantified according to their believed monetary value. The SPECA model developed is based on the LCOE equation described by Equation 1 which is further broken down as shown by Equation 2.

$$
\begin{aligned}
& L C O E=\frac{\text { Total life cycle cos ts }}{\text { Total life time energy production }} \\
& L C O E=\left\{\sum_{t=0}^{T} \frac{C_{t}}{(1+r)^{t}}\right\} /\left\{\sum_{t=1}^{T} \frac{E_{t}}{(1+r)^{t}}\right\}
\end{aligned}
$$

LCOE represents the cost of electricity that would match the cash inflows and the cash outflows normalized over the lifespan of the plant. This important metric allows the independent power producers (IPPs) to fully recover all the costs of the plant over a predetermined period of time $[15,16]$. The LCOE of an energy generating unit is usually determined at the point where the sum of all the discounted revenues equalizes with the sum of all the discounted cost as described by Equation 3. 
$\sum_{t=1}^{T} \frac{R_{t}}{(1+r)^{t}}=\sum_{t=0}^{T} \frac{C_{t}}{(1+r)^{t}}$

Unlike the modelling done in HOMER, the LCOE Equation 4 adopted by the SPECA model has included the externalities $\sum_{i=k}^{k} E C$ (social, environmental and economic) of solar PV in the computation of $L C O E$ and other metrics such as energy generated, cash flows among others.

$$
L C O E=\frac{I C-\sum_{t=1}^{T} \frac{D E P+I N T}{(1+D R)^{n}} T R+\sum_{t=1}^{T} \frac{L P}{(1+D R)^{t}}+\sum_{t=1}^{T} \frac{O \& M}{(1+D R)^{t}}(1-R O I)-\frac{R V}{(1+D R)^{t}}+\frac{\sum_{\mathrm{i}=\mathrm{k}}^{\mathrm{k}} \mathrm{EC}}{(1+D R)^{t}}+R C}{\frac{\sum_{n=1}^{N} S^{t} *(1-S D R)^{t}}{(1+D R)^{t}}}
$$

\subsection{SPECA Model Architecture}

The SPECA model provides an interactive GUI platform developed using visual basic programming while SQL has been used for database development. The system has the user interface and the database. The GUI is window based that provides functions to manipulate the data according to the requirements. The interface calls stored procedures and views heavily for data processing and data retrieval. Finally, the database stores all system data and none is held outside the database enhancing data integrity. The process flow diagram of the SPECA model is described by Figure 1.

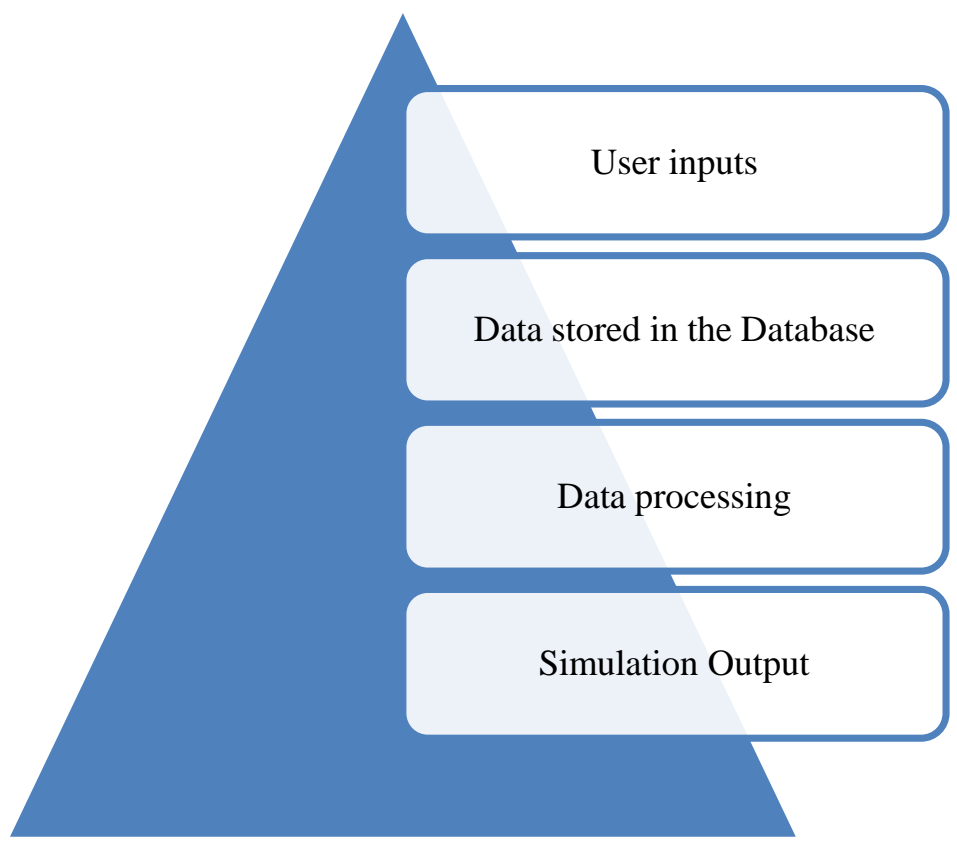

Figure 1. SPECA Model system Architecture

The database used is a relational database management system which is a Microsoft SQL server. The database stores the tabular files of DNI, cost of equipment's used for solar photovoltaic and their types, different environmental aspects of the different regions in Kenya, batteries, inverters etc. Figure 2 shows main features of the SPECA model derived from Equation 4.

Table 1. SPECA and HOMER Economic Inputs

\begin{tabular}{cc}
\hline Component & Amount \\
\hline Discount rate & $7.5 \%$ \\
Expected inflation rate & $7 \%$ \\
Project lifespan & 25 years \\
land cost/acre (for SPECA model) & Area dependent variable \\
Residual value (SPECA model) & $4.5 \%$ of CAPEX \\
\hline
\end{tabular}




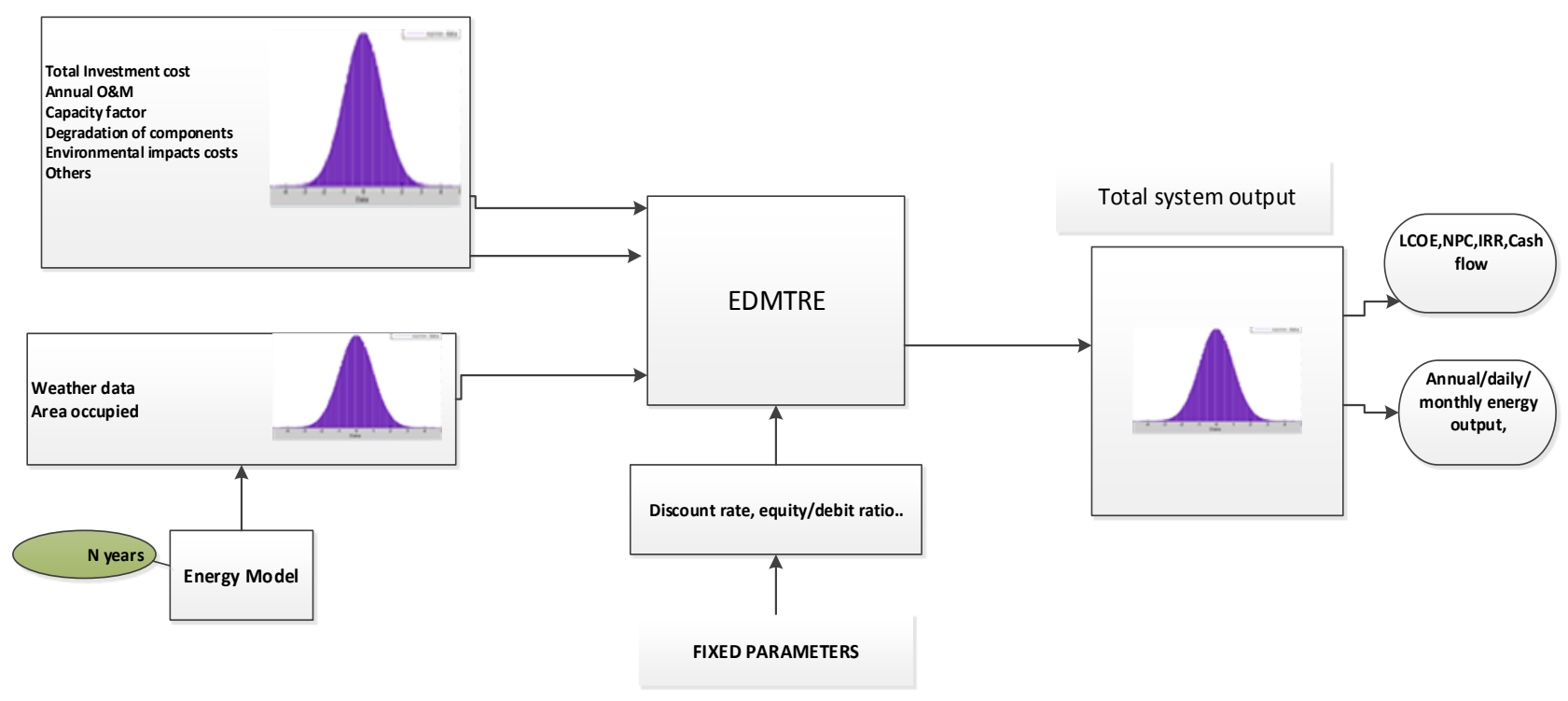

Figure 2. SPECA Model Block Diagram

\section{Criterion of Sizing Solar PV using SPECA Model}

The economic criteria used in the sizing of the solar PV depend on the load demand. In this paper the load demand of a typical village in Turkana district was estimated as shown in Table 5 which was used as an input to the SPECA model to determine the number of solar panels required and the batteries. Solar PV system includes different components that should be selected according to the system type, site location and applications. The major components for solar PV system are the PV module, inverter and the battery bank.

The sizing procedure described herein mostly applies for the SPECA model. The mathematical sizing procedure used in HOMER is hardly discussed in literature and hence sizing is done by the software itself. The user chooses the location, load requirements, components, and type of fuel, and once the system is run, HOMER calculates the LCOE, NPV, and the energy produced.The procedure followed by the SPECA model for sizing the PV and batteries is described in the flowing section.

\subsection{Sizing of a Standalone PV System}

For convenience and accurate sizing of a PV system, the specific area, Direct Normal Irradiance (DNI) data and the anticipated load are defined. The size of the PV system, total number of PV panels and the number of batteries are then calculated. As such several factors considered are the amount of energy $(\mathrm{kWh})$ that can be generated by the solar $\mathrm{PV}$ to meet the load demand, the Ah of the batteries required and the area occupied. There are several sizing techniques used previously in literature such as intuitive, numerical, analytical, commercial computer tools, artificial intelligence and the hybrid methods [17]. The numerical technique has been used in this paper for sizing the PV system because of its known accuracy and ability to easily use the linear functions unlike other tools [17].

The energy delivered by a solar PV array is given by:

$P_{a c}=P_{d c, S T C} * \eta$

Where

$P_{a c}=$ Actual ac power delivered;

$P_{d c, S T C}=$ Rated dc power output under standard test conditions;

$\eta=$ Conversion efficiency which accounts for inverter efficiency, dirt, PV collectors efficiency and mismatch factor.

\subsection{Steps Followed in Sizing the PV Array}

The insolation data $\left(\mathrm{kWh} / \mathrm{m}^{2}\right)$ for the different sites used in the SPECA model are obtained from the NASA websites. The worst month (month with the lowest solar irradiance) of the year is used for design. As shown by Equation 6 identification of a PV module and using its rated current IR together with its coulomb efficiency of about 0.9 and a derating factor (DR) of 0.9 and the Direct Normal Irradiance (DNI) of the design month, the Ah/day produced by each solar PV string is determined. 
Ah $/$ day - string $=D N I\left(k W h / m^{2}\right) * I_{R} * D R 0$

The number of parallel strings is given by Equation 7 .

Strings in parallel $=\frac{\text { design month load }(\text { Ah } / \text { day })}{A h / \text { day per } \bmod \text { ule in design month }}$

The number of PV modules in series is determined by Equation 8 .

$\bmod$ ules in series $=\frac{\text { system voltage }(V)}{\text { No } \min \text { al } \bmod \text { ule voltage }(V)}$

\subsection{Determination of Collector Area}

The size of area occupied and the number of PV cells varies according to type, as each has different parameters. Amount of energy delivered by a cell PV is described by Equations 9 and 10 .

$T_{\text {cell }}=T_{\text {ambient }}+\left(\frac{N O C T-T_{a v}}{0.8}\right) . . * D N I_{S T C}$

Where

$D N I_{S T C}=$ Insolation under standard test conditions $\left(\mathrm{kWh} / \mathrm{m}^{2}\right)$;

NOCT $=$ Nominal Operating Cell Temperature;

$T_{a v}=$ Average maximum daily temperature.

$P_{d c}=P V_{\text {rating }}\left[1-P_{l}\right]\left(T_{\text {cell }}-T_{\text {ov }}\right)$

Where

$P_{d c}=$ Solar PV DC output power;

$P V_{\text {rating }}=$ Rating of the solar PV;

$P_{l}=$ Power loss per degree above $T_{o v}$.

Including the dirt, mismatch and inverter efficiencies will result in an estimated ac rated power of the solar photo voltaic $\left(P_{a c}\right)$ shown by Equation 11 .

$P_{a c}=P_{d c} *$ mismatch $*$ dirt $*$ inverter $\eta$

The collector area is governed by the yearly energy yield and the yearly energy demand as described by Equations 12 to 15 .

$$
\begin{aligned}
& E D / y r=P_{a c} * D N I_{\text {site }} / \text { day } * C F * 365 \text { days } \\
& P_{a c}=\frac{E D / y r}{D N I_{\text {site }} / \text { day } * C F * 365 \text { days }} \\
& P_{d c}=\frac{P_{a c}}{\text { Mismatch } * \text { dirt } * \text { inverter efficiency }} \\
& \text { Area occupied }=\frac{P_{d c}}{D N I_{\text {site }} / \text { year } * \text { collector efficiency }}
\end{aligned}
$$

The different types of solar photovoltaic panels used in the development of the SPECA model are as shown in Table 2. 
Table 2. Types of Solar PV and their Characteristics

\begin{tabular}{ccccc}
\hline Module type & $\begin{array}{c}\text { Sharp NE } \\
\text { K125U2 }\end{array}$ & $\begin{array}{c}\text { Kyocera } \\
\text { KC158G }\end{array}$ & $\begin{array}{c}\text { Shell } \\
\text { SP150 }\end{array}$ & $\begin{array}{c}\text { Unisolar } \\
\text { SSR256 }\end{array}$ \\
\hline Material & Poly crystal & Multicrysta & Mono crystal & Triple junc \\
Rated power $\left(\mathrm{P}_{\mathrm{dc}}\right)$ & $125 \mathrm{~W}$ & $158 \mathrm{~W}$ & $150 \mathrm{~W}$ & $256 \mathrm{~W}$ \\
Voltage max & $26 \mathrm{~V}$ & $23.5 \mathrm{~V}$ & $34 \mathrm{~V}$ & $66 \mathrm{~V}$ \\
Max Current & $4.8 \mathrm{~A}$ & $6.82 \mathrm{~A}$ & $4.4 \mathrm{~A}$ & $3.9 \mathrm{~A}$ \\
O/C voltage & $32.3 \mathrm{~V}$ & $28.9 \mathrm{~V}$ & $43.4 \mathrm{~V}$ & $95.2 \mathrm{~V}$ \\
S/C voltage & $5.46 \mathrm{~A}$ & $7.58 \mathrm{~A}$ & $4.8 \mathrm{~A}$ & $4.8 \mathrm{~A}$ \\
Length $(\mathrm{m})$ & 1.19 & 1.29 & 1.619 & 11.124 \\
Width $(\mathrm{m})$ & 0.792 & 0.99 & 0.814 & 0.42 \\
Efficiency & $13.3 \%$ & $12.4 \%$ & $11.4 \%$ & $5.5 \%$ \\
Capital cost $(\$$ & 525 & 663.6 & 630 & 1075 \\
Deratiing $\%$ & $90 \%$ & $90 \%$ & $90 \%$ & $90 \%$ \\
Replacement $\$$ & 525 & 663.6 & 630 & 1075 \\
Lifespan $(\mathrm{yrs}$ & 25 & 25 & 25 & 25 \\
O\&M cost $(\$)$ & 121.25 & 153.26 & 145.5 & 248.32 \\
\hline
\end{tabular}

\subsection{Battery Storage}

The different types of batteries are as shown Table 3 .

Table 3. Types of Batteries and their Characteristics

\begin{tabular}{cccccc}
\hline Battery & MDOD $(\%)$ & Cycle life (cycles) & Lifespan (Years) & Eff. \% & Cost $\mathbf{( \$ \mathbf { k w h } )}$ \\
\hline Lead acid & $20 \%$ & 500 & $1-2$ & 90 & 50 \\
Golf cart Lead & $80 \%$ & 1000 & $3-5$ & 90 & 60 \\
Deep cycle & $80 \%$ & 2000 & $7-10$ & 90 & 100 \\
Nickel-cadmiu & $100 \%$ & $1000-2000$ & $10-15$ & 70 & 1000 \\
Nickel-hydride & $100 \%$ & $1000-2000$ & $8-10$ & 70 & 1200 \\
\hline
\end{tabular}

The battery storage capacity is determined by Equation 16 .

battery storage capacity $=\frac{A h / \text { day } * \text { days of autonomy }}{M D O M * D R}$

Where

$M D O M=$ maximum depth of discharge;

$D R=\%$ discharge rate.

\section{Quantification of Land Use Impacts}

Land Use Changes (LUC) all over the world remains to be one of the greatest contributing factor to the drastic biodiversity loss and extinction [18, 19]. The SPECA model has adopted countryside Species Area Relationship (SAR) for quantification of the number of species in the areas occupied by the USSE. The SAR model has been extensively used for describing the species richness existing in different localities across the world [18]. The SAR model is described by Equation 17.

$S_{\text {org }}=c A_{\text {org }}{ }^{z}$

Where

$S_{\text {org }}=$ Total number of species in a given area;

$c=$ Constant that depends on the taxonomic group and region being studied;

$A_{\text {org }}=$ Area occupied by the USSE (transformed land);

$z=$ A constant that depends on the sampling regime and scale. 
The species that remain after land is converted from one form to another is estimated using Equation 18.

$S_{n e w}=C A_{n e w}{ }^{z}$

The quotient of Equations 17 and 1) yields Equation 19.

$\frac{S_{\text {new }}}{S_{\text {org }}}=\left(\frac{A_{\text {new }}}{A_{\text {org }}}\right)^{z}$

The multiplication of Equation 19 by $S_{\text {org }}$ yields Equation 20.

$S_{\text {new }}=S_{\text {org }}\left(\frac{A_{\text {new }}}{A_{\text {org }}}\right)^{z}$

Subtracting Equation 20 from the original number of species that existed before the land use change yields the prediction of the extinctions as indicated by Equation 21.

Table 4. Valuation of Ecosystem Goods and Services [20]

\begin{tabular}{lc}
\hline Ecosystem Goods and services & Valuation (\$)/ha \\
\hline Regulating functions of ecosystems & $7-265$ \\
\hline 1 Regulating air & $88-268$ \\
2 Climate change & $2-7240$ \\
3Disturbing ecosystems goods and services & $2-5445$ \\
4 Water uptake and usage & $3-7600$ \\
5 water supply & $29-245$ \\
6 Soil erosion & $1-10$ \\
7 Soil maturity and formation & $87-21,100$ \\
8 soil nutrients recycling & $14-25$ \\
9 plants pollination & $2-78$ \\
\hline 10. Biological control & \\
\hline Habitat provision & $3-1523$ \\
\hline 11 habitation services & $142-195$ \\
\hline 12 Nursery function & $6-2761$ \\
\hline Bleeding and production services & $6-1014$ \\
\hline 13 food & $6-1014$ \\
\hline 14 Raw materials such as wood, charcoal & $6-112$ \\
\hline 16medicinal value & $6-112$ \\
\hline & \\
\hline
\end{tabular}

$S_{\text {org }}-S_{\text {new }}=S_{\text {org }}-S_{\text {org }}\left(\frac{A_{\text {new }}}{A_{\text {org }}}\right)^{z}$

In this paper the $z$ takes the values of $0.25-0.35$ while $c$.

After the conceivable damages have been identified the, restoration cost approach will be used to perform damage evaluation as shown in Equation 22.

$C=\sum_{i} V_{i} * X$

Where $\mathrm{C}$ is the total external cost, $V$ is the value of each external cost and $X$ represents the number of impacts of USSE 
considered in a certain region. The international standards of ecosystem goods and services are expressed in $\$ /$ ha/year and were estimated according to Groot et al. [17] as shown in Table 4.

\subsection{Accounting for Human Health Damages}

The SPECA model developed in this paper accounts for morbidity and mortalities resulting from the installation of Solar PV. The work-related and non-work related accidents considered in this paper are for the non-organization for Economic Cooperation and Development countries where Kenya is classified into Nkambule and Blignaut (2017) study [21]. The per unit prices for treating persons suffering injuries or mortalities while working with USSE are based on the studies done by Friedrich et al. (2004) and Preiss and Klotz (2008) [22, 23]. Morbidity and mortality consists of two variables viz. unit morbidity value and the unit mortality value. The per unit morbidity value ( $U V_{\text {mod }}$ \$/person) is estimated using Equation 23.

$U V_{\mathrm{mod}}(t)=U V_{\mathrm{mod}}(1804)+\Delta U V_{\mathrm{mod}}(t)$

Where $\Delta U V_{\text {mod }}(t)$ is the change in morbidity value. The unit mortality values $\left(U V_{m o t}, \$ /\right.$ person) were obtained by Nkambule and Blignaut (2017) [21] and are described by Equation 24.

$U V_{\text {mot }}(t)=U V_{m o t}(17413)+\Delta U V_{m o t}(t)$

The unit mortality value and the unit morbidity value derive their costs from three phases i.e during construction, operation phase and the decommissioning phase. The parameters used for the two sub-models are described in Table 5.

Table 5. Mortality and Morbidity model values

\begin{tabular}{lcc}
\hline \multicolumn{1}{c}{ Parameter } & Unit & Value \\
\hline Unit mortality value & \$/person & 17413 \\
Unit Morbidity & \$/person & 1804 \\
Fatalities per million tons of concrete & Persons/million tons & 0.159 \\
Fatalities per million tons of steel & Persons/million tons & 2.0158923 \\
Fatalities per million tons of limestone & Persons/million tons & 0.2906977 \\
Fatalities per MWh & Persons /MWh & 0.00000026 \\
Injuries per MWh & Persons /MWh & 0.0000001 \\
\hline
\end{tabular}

\subsection{Water Consumption Model}

In solar PV water consumption is used for mirror washing. Water is mainly used during construction phase and in the generation phase. The unit cost of water use $\left(U W C, \$ / \mathrm{m}^{3}\right)$ is determined by the change in the opportunity cost of water use $\left(\triangle U W C, \$ / m^{3} / y r\right)$ and is estimated using Equation 25.

$U W C(t)=U W C(t)+\Delta U W C(t)$

The solar PV water externality cost is estimated using two costs, that is, opportunity cost of water during construction ( $U W C C\left(\$ / \mathrm{m}^{3}\right)$ and generation $(U W C G)$ shown by Equation 26.

USSECT $=O C W C+O C W G$

\section{Simulation Inputs for the SPECA Model}

It has been assumed in this paper that electricity generated by Solar PV belongs to an IPP (independent power producer) and therefore any electricity generated is owned by the IPP.

\subsection{Load}

The load data of Turkana district is determined by evaluating the existence of electrical appliances in a typical homestead which includes refrigerators, TV, stoves, micro waves among others. In this paper load data used as input for the SPECA model and HOMER software was derived from Table 6 and scaled up for 1000 households. 
Table 6. Typical Load of Turkana District

\begin{tabular}{ccccc}
\hline Appliance & Quantity & Rating $(\mathbf{k W})$ & (hrs/day) & Daily consumption $(\mathbf{k W h})$ \\
\hline Fridge (14.cu ft) & 1 & 0.3 & 24 & 7.2 \\
Television (19-in) & 2 & 0.068 & 8 & 1.088 \\
Electric Kettle & 1 & 1 & 0.5 & 0.5 \\
Desktop computer & 1 & 0.3 & 6 & 1.8 \\
Laptop & 2 & 0.036 & 6 & 0.432 \\
Lights & 10 & 0.03 & 5 & 1.5 \\
Security Lights & 2 & 0.045 & 8 & 0.72 \\
Geyser & 1 & 3 & 1 & 3 \\
Heater & 2 & 2 & 3 & 12 \\
Microwave & 1 & 1 & 0.33 & 0.33 \\
\hline Total & & & & $28.57 * 100=2857$ \\
\hline
\end{tabular}

The resulting load profile is described by Figure 3 with an average hourly load of $119.04 \mathrm{~kW} / \mathrm{hr}$.

Daily Profile

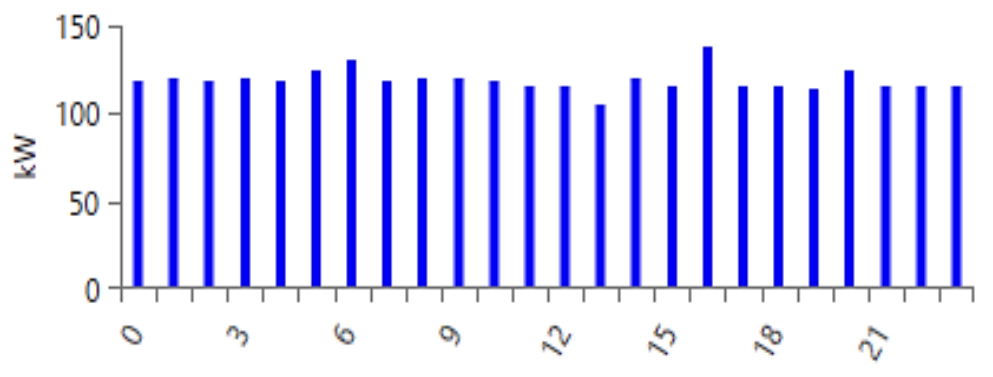

Figure 3. Load Profile of Turkana District

\subsection{Resources}

The site selected for the simulation is Turkana District which is $3^{0} 18.7^{\prime} \mathrm{N}, 35^{0} 33.9^{\prime} \mathrm{E}$. HOMER and SPECA model requires the solar insolation data as an input for electricity for electricity generation from PV. The weather patterns of the different regions across the globe are inbuilt in HOMER and therefore once a site is selected, its weather data is loaded as well. The solar insolation Data is shown by Figure 4.
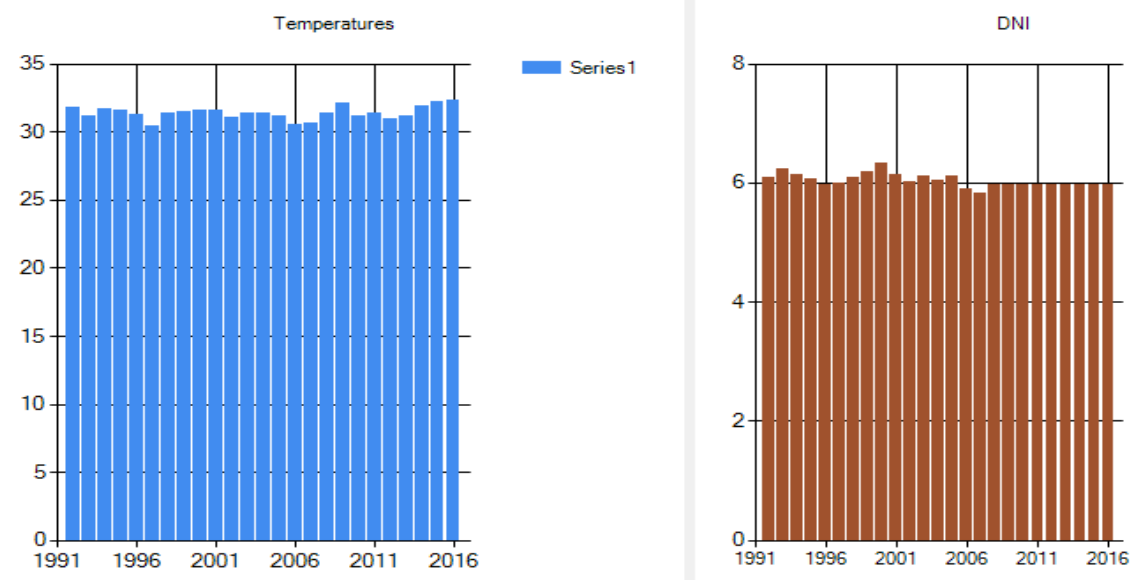

Figure 4. Temperature and DNI of Turkana using SPECA modelling tool

\section{Costs Considered}

The basic criterion related to the selection of the power system components in this paper is the cost of components, because the main purpose of the work is searching the optimum power system configuration that would meet the demand with minimum NPC and COE. The estimation of the components cost was made based on the current cost available in the market. In this paper the all component costs and specifications were adopted from [24]. In the 
HOMER and SPECA model the user can change the component cost based on the market trend. The different types of component cost are:

- Initial capital cost of components: It is the total installed cost deployed to purchase and install the component at the commencement of the project.

- O\&M cost: It is the cost accounted for maintenance and operation of the system. The entire scheme components considered in this paper has different operation and maintenance costs. Miscellaneous O\&M costs considered by HOMER are like emission penalties, capacity shortage penalty and fixed operation and maintenance costs. The determination of the emission penalties and capacity shortage penalty used by HOMER is mathematically inbuilt in the software and hence no mathematical models available as the software does not provide them to the public. For the SPECA model, the emissions are accounted for as described in sections above which includes water consumption, land usage, impacts on health and ecosystems.

- Replacement cost: This is the cost required to replace wear out components at the end of its life cycle. This cost is different from initial cost of the component, due to the fact that different components have different life times. There are some components that will run in the entire lifespan of the plant whereas some will be replaced midway.

\section{Results and Analysis}

In this section the simulation results obtained from SPECA model and HOMER software for Turkana District are discussed and compared. The two software calculates the output based on the procedure mentioned in the methodology and the results of each software are described in the following sections.

\subsection{SPECA Modelling Tool Results}

The SPECA modelling displayed results of yearly energy generated from 1992-2016 as shown in the diagram. The energy delivered varies according to the DNI estimated at $1800 \mathrm{kWh} / \mathrm{m}^{2} / \mathrm{yr}$. Figure 5 shows the yearly energy generated during the lifespan of the plant. The random variability of the solar resource leads to the uneven energy production in the different years.

The area required for installation to meet the electricity demand was estimated to be 5130 acres of land that required about 4008 solar photovoltaic panels and 394 batteries. The cascaded impacts on land as a result of this land occupation includes diseases like Cancer which results from emission of some hazardous gases such as particulate matter, lead, VOC among others. The SPECA modelling tool estimated the NPC including the externalities (environmental and health costs) to a tune of $\$ 2.07$ billion for a period of 25 years The environmental cost included were the cost of land and the various function of land in this particular region as was described in Table 3 . The SPECA tool determines the cost of a disease using two functions described above, that is, unit morbidity value and unit mortality values.

Energy Delivered KW

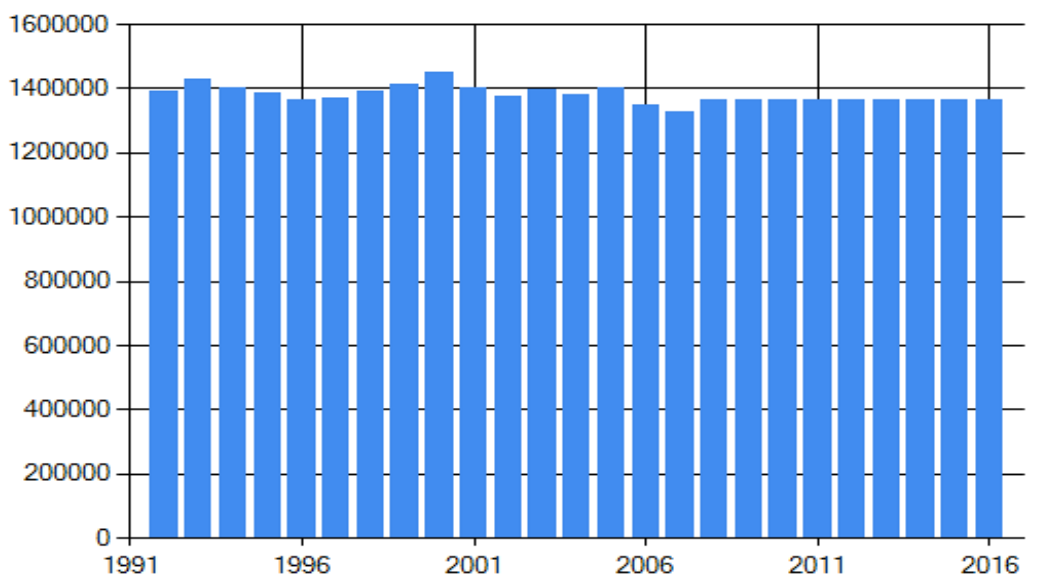

Figure 5. Yearly Energy Generated

SPECA model further determines the LCOE to be about $\$ 3.81$. As discussed earlier LCOE is a function of the Life cycle costs (LCC) and the energy generated. The SPECA model is among the first tools to accommodate the external costs of energy generation which in this case are the environmental costs and the health costs. The cash inflow and cash outflow for the whole period is shown in Figures 6 and 7. The cash flow is highest at the beginning of the project and minimum near the end of the lifespan. 


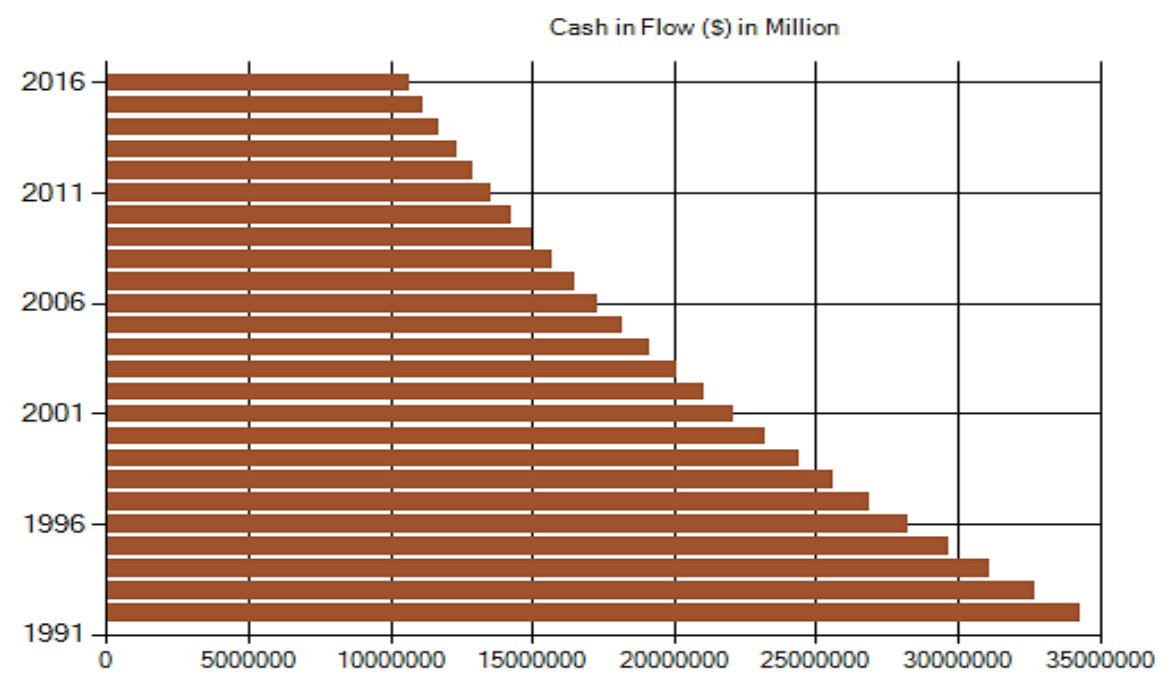

Figure 6. SPECA Model Cash Inflow

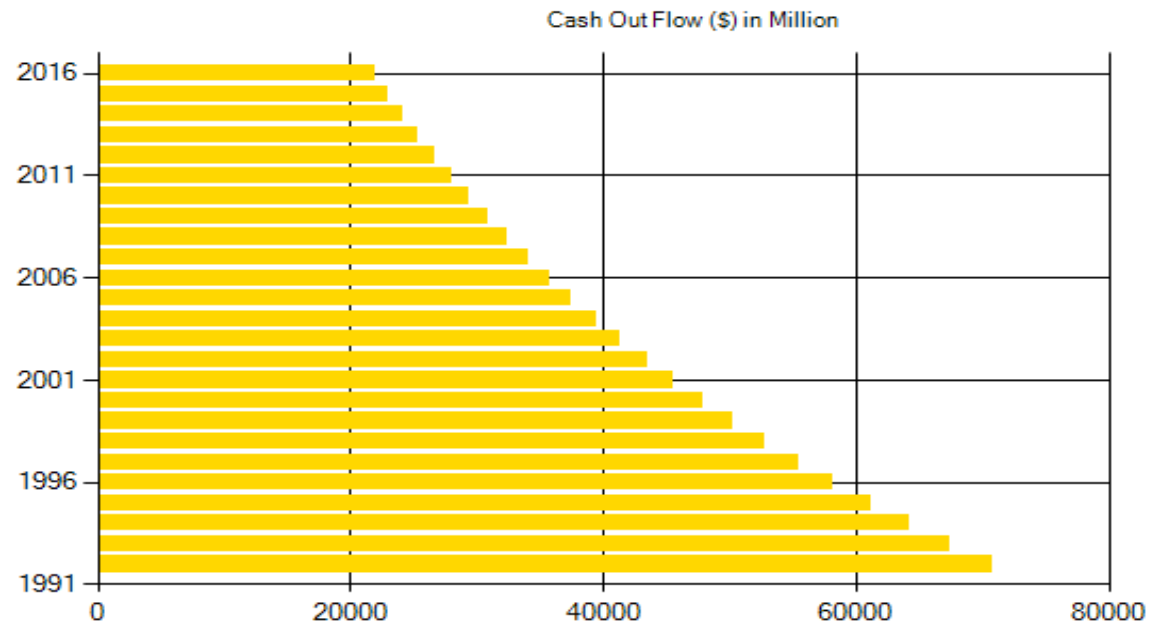

Figure 7. SPECA Model Cash outflow

\subsection{HOMER Results}

HOMER simulation estimated the total NPC to $\$ 1.7$ billion while the optimal LCOE was $\$ 1.07$. HOMER found the optimal LCOE by considering 138 combinations in which only 66 cases were feasible. The resultant of the input output cash-flow is as shown in Figure 8. In the cash-flow the plant breaks-even on the final year of production where the cash-flow is positive.

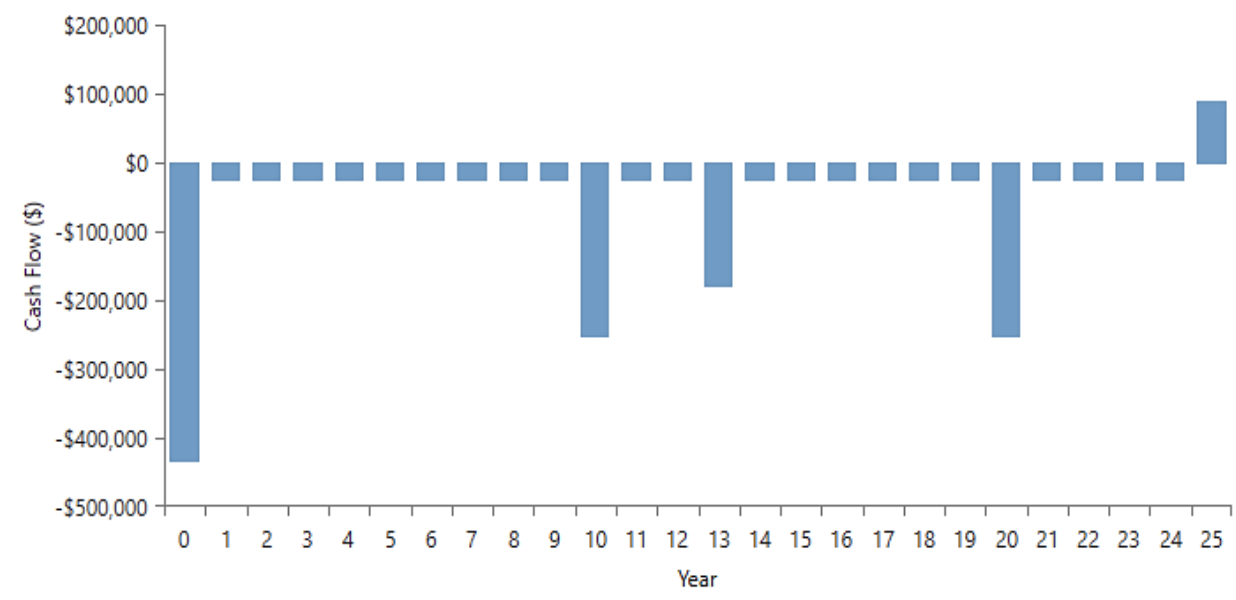

Figure 8. HOMER Cash flow 


\subsection{Results Comparison}

The results are compared in terms of environmental impact analysis, health impact analysis and the general economics. A variety of greenhouse gases are also emitted from solar during generation as reported in literature [25]. The SPECA model considers a variety of them including PM, ammonia, $\mathrm{CO}_{2}$, nickel, mercury, methane, and lead among others. Also, in the SPECA modelling tool the land occupied is quantified according size, type vegetation, economic worth measured in terms of $\$ /$ Hectare/ year. The different monetary value of land use types were obtained from the Ecosystem service value database (EVSD). The EVSD allocates monetary value to the different types of land occupation per Hectare per year. The SPECA model is equipped with SQL database that contains this data and is always recalled during calculation. On the other hand HOMER considers only the carbon Dioxide [4], which in not monetized. LCOE for the SPECA model is $70 \%$ more than that of HOMER which has been attributed to lack of monetization of the land costs, environmental cost and the social costs.

\section{Conclusion and Recommendations}

In this paper, HOMER and the SPECA modelling tool have been used to size solar photovoltaic systems for Turkana District. The result analysis provides a base for comparison of the two packages. The SPECA model is a new tool and has not been explored as much as the HOMER software. HOMER is user-friendly, flexible, and good at sizing HRES according to resource availability. The LCOE yield in HOMER is slightly low. However, during the sizing of the most optimal combination of HRES, HOMER does not consider basic things like land cost and size, environmental impacts costs, and social impacts costs. It is the opinion of the authors of this paper that if these key costs were considered in HOMER, the LCOE and NPC of the two packages would match. The other possible discrepancy with the results is that HOMER determines the NPC of a component as the present value of all the costs incurred during purchasing, installing, and operating the component minus all the revenues generated by the product. On the other hand, the SPECA modelling tool does not consider the revenue from solar PV.

Research and development should be geared towards improving the SPECA model software to accommodate more than one energy resource type to enhance hybridization of renewable energy systems. In general, SPECA will be of great use to investors and policy makers of Solar PV systems for drawing alternatives and conclusions based on the best compromise. The model developed will be useful especially in addressing the trade-offs between environmental impacts, financial impacts which are all aimed in the improvement of the quality and transparency in the decisionmaking during deployment of Solar PV. The quantification of the social-environmental impacts of Solar PV will permit for a cost accounting assessment of the unforeseen costs incurred when using them for electricity generation.

\section{Acknowledgement}

The authors would like to thank the Technical University of Mombasa for providing infrastructure to carry out this study.

\section{Declaration of Competing Interest}

The authors declare that they have no known competing financial interests or personal relationships that could have appeared to influence the work reported in this paper.

\section{References}

[1] Painuly, J. P. (2001). Barriers to renewable energy penetration; a framework for analysis. Renewable Energy, 24(1), 73-89. doi:10.1016/s0960-1481(00)00186-5.

[2] Burtraw, D., Krupnick, A., Sampson, G., \& Beasley, B. (2012). The True Cost of Electric Power. RFF Report, Resources for the Future, Washington, DC, United States.

[3] Connolly, D., Lund, H., Mathiesen, B. V., \& Leahy, M. (2010). A review of computer tools for analysing the integration of renewable energy into various energy systems. Applied Energy, 87(4), 1059-1082. doi:10.1016/j.apenergy.2009.09.026.

[4] Acakpovi, A., Hagan, E. B., \& Michael, M. B. (2015). Cost benefit analysis of self-optimized hybrid solar-wind-hydro electrical energy supply as compared to HOMER optimization. International Journal of Computer Applications, 114(18), 32-38.

[5] Rawat, R., \& Chandel, S. S. (2013). Simulation and optimization of solar photovoltaic-wind stand-alone hybrid system in hilly terrain of India. International Journal of Renewable Energy Research (IJRER), 3(3), 595-604.

[6] Amer, M., Namaane, A., \& M'Sirdi, N. K. (2013). Optimization of Hybrid Renewable Energy Systems (HRES) Using PSO for Cost Reduction. Energy Procedia, 42, 318-327. doi:10.1016/j.egypro.2013.11.032.

[7] Bansal, A. K., Gupta, R. A., \& Kumar, R. (2011). Optimization of hybrid PV/wind energy system using Meta Particle Swarm Optimization (MPSO). India International Conference on Power Electronics 2010 (IICPE2010), New Delhi, India. doi:10.1109/iicpe.2011.5728079. 
[8] Ram, G. N., Shree, J. D., and Kiruthiga, A. (2013). Cost Optimization of Standalone Hybrid Power Generation System, International Journal of Advanced Research in Electrical, Electronics and Instrumentation Engineering, 2(8), 4048-4057.

[9] Lotfi, S., Tarazouei, F. L., \& Ghiamy, M. (2013). Optimal design of a hybrid solar-wind-diesel power system for rural electrification using imperialist competitive algorithm. International Journal of Renewable Energy Research (IJRER), 3(2), 403411.

[10] Sharma, D., Gaur, P., \& Mittal, A. P. (2014). Comparative Analysis of Hybrid GAPSO Optimization Technique with GA and PSO Methods for Cost Optimization of an Off-Grid Hybrid Energy System. Energy Technology \& Policy, 1(1), $106-114$. doi:10.1080/23317000.2014.969450.

[11] Idoumghar, L., Melkemi, M., Schott, R., \& Aouad, M. I. (2011). Hybrid PSO-SA Type Algorithms for Multimodal Function Optimization and Reducing Energy Consumption in Embedded Systems. Applied Computational Intelligence and Soft Computing, 2011, 1-12. doi:10.1155/2011/138078.

[12] Ekren, B. Y., \& Ekren, O. (2009). Simulation based size optimization of a PV/wind hybrid energy conversion system with battery storage under various load and auxiliary energy conditions. Applied Energy, 86(9), 1387-1394. doi:10.1016/j.apenergy.2008.12.015.

[13] Barakat, S., Samy, M. M., Eteiba, M. B., \& Wahba, W. I. (2016). Feasibility Study of Grid Connected PV-Biomass Integrated Energy System in Egypt. International Journal of Emerging Electric Power Systems, 17(5), 519-528. doi:10.1515/ijeeps-20160056.

[14] Ashok, S. (2007). Optimised model for community-based hybrid energy system. Renewable Energy, 32(7), $1155-1164$. doi:10.1016/j.renene.2006.04.008.

[15] Mohamed, E. S. (2017). Economics of variable renewable sources for electric power production. Lap Lambert Academic Publishing, Sunnyvale, CA, USA.

[16] Namovicz, C. (2013). Assessing the economic value of new utility-scale renewable generation projects. In EIA Energy Conference, 1-20. U.S. Energy Information Administration, Washington, DC, USA.

[17] Khatib, T., Ibrahim, I. A., \& Mohamed, A. (2016). A review on sizing methodologies of photovoltaic array and storage battery in a standalone photovoltaic system. Energy Conversion and Management, 120, $430-448$. doi:10.1016/j.enconman.2016.05.011.

[18] Chaudhary, A., Verones, F., De Baan, L., \& Hellweg, S. (2015). Quantifying land use impacts on biodiversity: combining species-area models and vulnerability indicators. Environmental Science \& Technology, 49(16), 9987-9995. doi:10.1021/acs.est.5b02507.

[19] Pereira, H. M., Ziv, G. U. Y., \& Miranda, M. (2014). Countryside species-area relationship as a valid alternative to the matrixcalibrated species-area model. Conservation Biology, 28(3), 874. doi:10.1111/cobi.12289.

[20] Wilson, M. A., Costanza, R., Boumans, R., \& Liu, S. (2005). Integrated assessment and valuation of ecosystem goods and services provided by coastal systems. The intertidal ecosystem: the value of Ireland's shores. Royal Irish Academy, 1-24.

[21] Nkambule, N. P., \& Blignaut, J. N. (2017). Externality costs of the coal-fuel cycle: The case of Kusile Power Station. South African Journal of Science, 113(9-10), 1-9. doi:10.17159/sajs.2017/20160314.

[22] Friedrich, R.; Rabl, A., Hirschberg, S., Desaigues, B., Markandya, A., de Nocker, L. (2004). New elements for the assessment of external costs from energy technologies. In EU 5th Framework Programme; Institute for Energy Economics and the Rational Use of Energy: Stuttgart, Germany.

[23] Preiss, P., \& Klotz, V. (2008). NEEDS New Energy Externalities Developments for Sustainability. Technical Paper no. 7.4RS 1b."Description of updated and extended draft tools for the detailed site-dependent assessment of external costs". Universität Stuttgart, Germany.

[24] Masters, G. M. (2013). Renewable and Efficient Electric Power Systems. John Wiley \& Sons, New York, United States.

[25] Moss, J., Coram, A., \& Blashki, G. (2014). Solar Energy in Australia: Health and environmental Costs and Benefits of Solar energy in Australia. The Australia Institute, Canberra, Australia. 